\title{
MATERNAL RACIAL ORIGIN AND PREECLAMPSIA: COHORT STUDY AND SYSTEMATIC REVIEW WITH META-ANALYSIS
}

\author{
Anastasija ARECHVO ${ }^{1}$, Diana VOICU ${ }^{1}$, Mar Gil $^{2}$, Argyro Syngelaki ${ }^{1}$, Ranjit Akolekar ${ }^{3}$, \\ and Kypros Nicolaides ${ }^{4}$ \\ ${ }^{1}$ King's College Hospital \\ ${ }^{2}$ Hospital Universitario de Torrejon \\ ${ }^{3}$ Medway Maritime Hospital \\ ${ }^{4}$ Fetal Medicine Institute
}

February 2, 2022

\begin{abstract}
Objectives: To examine the association between racial origin and preeclampsia(PE) and gestational hypertension(GH) after adjustment for factors in maternal characteristics and medical history in screening study from the Fetal Medicine Foundation (FMF) in England, and to perform a systematic review and meta-analysis of studies on PE. Methods: In the FMF data regression analysis was performed to examine the association between racial origin and PE or GH. Literature search to December 2021 was carried out to identify peer-reviewed publications on race and PE. Main outcome measure: Relative risk of PE and GH in women of black, South Asian and East Asian racial origin by comparison to white women. Results: In the FMF study there were 168,966 singleton pregnancies without major abnormalities delivering at [?]24 weeks' gestation. In black women the respective risk of total-PE and preterm-PE was 2-fold and 2.5-fold higher and risk of GH was $25 \%$ higher, in South Asian women there was a 1.5-fold higher risk of preterm-PE but not total-PE, and in East Asian women there was no significant difference in risk of hypertensive disorders. The literature search identified 19 studies that provided data on several million of pregnancies, but 17 were at moderate or high-risk of bias and only three provided risks adjusted for some maternal characteristics; consequently, these studies did not provide accurate contribution of different racial groups to the prediction of PE. Conclusion: In women of black and South Asian origin the risk of PE, after adjustment for confounders, is higher than in white women
\end{abstract}

\section{INTRODUCTION}

Preeclampsia (PE), which complicates $2-4 \%$ of pregnancies, is associated with a global annual rate of about 75,000 maternal deaths and 500,000 baby deaths. ${ }^{1,2}$ The risk for development of PE is related to several maternal characteristics, including age, weight, racial origin, method of conception, prior and family history of $\mathrm{PE}$, and pre-existing medical conditions, such as chronic hypertension, diabetes mellitus and autoimmune disease. ${ }^{3}$

Studies from countries with populations that are of predominantly white racial origin have consistently reported that in minority groups, such as women of black racial origin, the incidence of PE is increased. ${ }^{4-19}$ In a small number of studies the incidence of PE in women of East Asian racial origin tended to be lower than in white women, whereas in South Asian women the incidence tended to be similar to that in white women..$^{9,12,15,16,20-22}$ However, in most of these studies the observed relative incidence of PE was not adjusted for confounding factors in maternal characteristics and medical history. In a previous study of 76,158 singleton pregnancies with a live fetus at $11^{+0}$ to $13^{+6}$ weeks, we adjusted for confounders and reported that 
in women of black and South Asian racial origin, but not in East Asian women, the incidence of PE was higher than in white women. ${ }^{23}$

The objectives of this extended study of 168,966 singleton pregnancies with a live fetus at $11^{+0}$ to $13^{+6}$ weeks are first, to examine the association between maternal racial origin and $\mathrm{PE}$ after adjustment for confounding factors in maternal demographic characteristics and medical history in the data from the Fetal Medicine Foundation (FMF), and second, to carry out a systematic review of the literature and meta-analysis of all studies on this topic.

\section{METHODS}

\section{FETAL MEDICINE FOUNDATION STUDY}

\section{Study design and participants}

The data were derived from prospective screening for pregnancy complications in women with singleton pregnancies attending their first routine hospital visit at $11+0$ to $13+6$ weeks of gestation at King's College Hospital, London or Medway Maritime Hospital, Kent from March 2006 to November 2020. The visit included recording of maternal demographic characteristics and medical history, measurement of maternal weight and height and ultrasound examination for the measurement of the fetal crown-rump length (CRL) and to determine gestational age ${ }^{24}$, measurement of the fetal nuchal translucency thickness, as part of screening for trisomies ${ }^{25}$, and examination of the fetal anatomy for the diagnosis of major fetal defects ${ }^{26}$.

Participants completed a questionnaire, which was then reviewed by a doctor together with the woman. Patient characteristics included maternal age, racial origin (white, black, South Asian, East Asian, and mixed), method of conception (natural or assisted by IVF or use of ovulation drugs), cigarette smoking during pregnancy, medical history of chronic hypertension, diabetes mellitus, systemic lupus erythematosus (SLE) or antiphospholipid syndrome (APS), family history of preeclampsia in the mother of the patient, and obstetric history that included parity (parous or nulliparous if no previous pregnancies at [?]24 weeks' gestation), previous pregnancy with PE and previous pregnancy with delivery of small for gestational age (SGA) neonate with birth weight $<10^{\text {th }}$ percentile of The Fetal Medicine Foundation fetal and neonatal population weight charts. $^{27}$

The inclusion criteria for this study were singleton pregnancies delivering a non-malformed live birth or stillbirth at [?]24 weeks' gestation. We excluded pregnancies with aneuploidies and major fetal abnormalities. Women gave written informed consent to take part in the study which was approved by the NHS Research Ethics Committee. There was no patient involvement in the design of the study.

\section{Study funding}

This study was supported by grants from the Fetal Medicine Foundation (UK Charity No: 1037116). Reagents and equipment for the measurement of serum placental growth factor were provided free of charge by Roche Diagnostics, and PerkinElmer Life and Analytical Sciences. These bodies had no involvement in the study design; in the collection, analysis and interpretation of data; in the writing of the report; and in the decision to submit the article for publication.

\section{Outcome measures}

Outcome measures were delivery with PE or GH. Data on pregnancy outcome were collected from the hospital maternity records or the general medical practitioners of the women. The obstetric records of all women with chronic hypertension or pregnancy associated hypertension were examined to determine the diagnosis of PE or GH. Diagnosis of GH was based on the finding of hypertension (systolic blood pressure of $>140 \mathrm{~mm}$ $\mathrm{Hg}$ or diastolic blood pressure of $>90 \mathrm{mmHg}$ on at least two occasions four hours apart developing after 20 weeks' gestation in previously normotensive women). Diagnosis of PE was based on the finding of new onset hypertension or chronic hypertension and at least one of the following: proteinuria ([?]300 $\mathrm{mg} / 24 \mathrm{~h}$ or protein to creatinine ratio $>30 \mathrm{mg} / \mathrm{mmoL}$ or $>2+$ on dipstick testing), renal insufficiency with serum creatinine $>97 \mu \mathrm{mol} / \mathrm{L}$ in the absence of underlying renal disease, hepatic dysfunction with blood concentration of 
transaminases more than twice the upper limit of normal ([?]65 IU/L for our laboratory), thrombocytopenia (platelet count $<100,000 / \mu \mathrm{L}$ ), neurological complications (e.g. cerebral or visual symptoms), or pulmonary edema. $^{28}$

\section{Statistical Methods}

Data were expressed as mean (standard deviation) for continuous variables and $\mathrm{n}(\%)$ for categorical variables. Students t-test and $\chi^{2}$-square test or Fisher's exact test, were used for comparing outcome groups for continuous and categorical data, respectively.

Univariable logistic regression analysis was performed to examine the association between racial origin and $\mathrm{PE}$ and GH using white racial origin as the reference. Multiple logistic regression analysis with manual backward elimination was performed for modelling total PE, preterm PE with delivery at $<37$ weeks of gestation, early PE with delivery at $<34$ weeks and total GH using racial origin, maternal age, weight, height, mode of conception, smoking, history of chronic hypertension, diabetes mellitus, APS or SLE, history of $\mathrm{PE}$ in a previous pregnancy or family history of PE. Before performing the multiple regression analysis, continuous variables were centered by subtracting the median from each measured value ( 67 from maternal weight in $\mathrm{kg}, 1.65$ from maternal height in meters and 30 from maternal age in years).

The statistical software $\mathrm{R}$ was used for data analyses. ${ }^{29}$

\section{SYSTEMATIC REVIEW AND META-ANALYSIS}

\section{Literature search and study selection}

Searches of Ovid Medline, Embase, CENTRAL (The Cochrane Library), Cinahl and Emcare were carried out to identify studies reporting on race and PE. The search was carried out on the $10^{\text {th }}$ August 2021 with no restriction for starting date but was restricted to English language records only; the initial search was updated with autoalerts in Medline to $31^{\text {st }}$ December 2021. A list of relevant citations was generated from these databases using the search strategies given in Appendix 1. This review was registered in PROSPERO international database for systematic reviews (reference: CRD42021267548).

The abstracts of citations were examined by two reviewers (A.A. and D.V.) to identify all potentially relevant articles, which were then examined in full-text form. Reference lists of relevant original and review articles were hand-searched for additional reports. Agreement about potential relevance was reached by consensus and by consultation with a third reviewer (K.H.N.). The inclusion criteria were peer-reviewed studies reporting on $\mathrm{PE}$ in singleton pregnancies according to the racial origin of women so that the rate of $\mathrm{PE}$ could be compared in black and South and East Asian women to the rate in white women. We excluded twin pregnancies, case-control studies and review articles or guidelines and articles in which PE and GH were not given separately.

\section{Data extraction and meta-analysis of data from all studies}

Data were obtained from each study included in the systematic review and documented in contingency tables. We extracted the necessary data to calculate the incidence of PE in white women and in each other racial group. Whenever possible, we extracted the reported relative risk (RR) or odds ratio (OR) and $95 \%$ confidence intervals (CIs) from each study. Where available we extracted separate RR estimates with different degrees of confounder adjustment for the following prespecified conventional risk factors (age, weight and height or body mass index, smoking status and parity). First, we used raw data to adjust random effect models for meta-analyses using inverse variance method for pooling and DerSimonian-Laird to estimate the between-study variance $(\tau 2)$. Second, we used adjusted OR from the included studies to also adjust the random effect model for meta-analysis with inverse variance for pooling but, in this case, we used restricted maximum-likelihood estimator (REML) for the between-study variance estimation. The pooled $\mathrm{RR}$ and/or pooled OR with $95 \%$ confidence intervals were estimated for race as a predictor for PE, using adjusted analysis as reported in the studies and a random effects model that considers both within- and 
between study variation ${ }^{30}$. Statistical heterogeneity among studies was evaluated using the $\mathrm{I}^{2}, \tau^{2}$ statistics and the $\mathrm{p}$ value of the Chi-Square test of $\mathrm{Q}^{31}$.

Publication bias, when the minimum number of included studies was 10, was assessed by plotting the RR estimate against precision (funnel plots) by Begg's adjusted rank correlation test, and by Egger's regression asymmetry test ${ }^{32,33}$.

Risk of bias assessment was made with quality in prognostic studies (QUIPS) tool ${ }^{34}$ presented and adjusted for this review. The following six domains were used: representativeness of study population, adequateness of follow-up period and attrition, appropriateness of racial origin classification, appropriateness of the definition of the outcome (PE), adequateness of statistical analysis and reporting. Each element was classified as low, moderate or high risk of bias. If two of the domains were assessed as having high risk of bias or four of the domains were assessed as having moderate risk of bias, then the overall risk of bias for a study was graded as high risk of bias. If three of the domains were assessed as having moderate risk of bias, or one domain was at high risk of bias and one was at moderate risk then the overall risk of bias was graded as moderate risk of bias. If all the domains within a study were graded as low risk of bias, or less than three were moderate and none was high, then the overall judgement for the study was low risk of bias.

Statistical software $\mathrm{R}^{35}$ was used in all analyses, package 'meta' ${ }^{36}$ and 'metafor' ${ }^{37}$ were used for the meta-analysis and package car ${ }^{38}$ to clean the data.

\section{RESULTS}

\section{Fetal Medicine Foundation study}

\section{Study population}

In the FMF study there were 168,966 singleton pregnancies with a live fetus at $11^{+0}$ to $13^{+6}$ weeks without major abnormalities that delivered at [?]24 weeks of gestation. In addition, there were 5,406 (3.1\% of the total) that were lost to follow up. The characteristics of the study population are summarized in Table 1. The pregnancies included 4,272 that developed PE, 4,344 that developed GH and 160,350 that did not develop either PE or GH. In the women of black racial origin, compared to white women, there was a higher median weight, higher incidence of PE and GH, chronic hypertension, type 2 diabetes mellitus and SLE or APS, and higher incidence of PE and SGA in a previous pregnancy, and lower incidence of conception by use assisted reproductive technologies and lower incidence of nulliparity. In the women of South Asian racial origin, compared to white women, there was a higher incidence of preterm PE, chronic hypertension, type 2 diabetes mellitus and SLE or APS, conception by in vitro fertilisation and higher incidence of SGA in a previous pregnancy. In the women of East Asian racial origin, compared to white women, there was a lower median weight, lower incidence of $\mathrm{GH}$, smoking, and incidence of PE in a previous pregnancy and higher incidence of diabetes mellitus type 2 and previous SGA.

\section{Odds ratio for preeclampsia and gestational hypertension}

The results of univariable and multiple logistic regression analysis demonstrating the association of maternal racial origin with $\mathrm{PE}$ and GH are shown in Table 2. The univariable logistic regression analysis demonstrated that first, women of black racial origin, compared with white women, had significantly higher rates of all PE, preterm PE, early PE and GH, second, women of South Asian origin, compared with white women, had significantly higher rates of preterm PE and early PE, but not all PE or GH, third, women of East Asian origin, compared with white women, had significantly lower rate of $\mathrm{GH}$, but not significantly different rates for all $\mathrm{PE}$, preterm $\mathrm{PE}$ or early $\mathrm{PE}$, and fourth, women of mixed origin, compared with white women, had no significantly different rates for all $\mathrm{PE}$, preterm PE, early $\mathrm{PE}$ or $\mathrm{GH}$.

The odds ratio for all $\mathrm{PE}$, preterm $\mathrm{PE}$, early $\mathrm{PE}$ and $\mathrm{GH}$ in black women, compared to white women, after adjustment for elements of maternal characteristics and medical history was 1.99 (95\% CI 1.85, 2.14), 2.58 (95\% CI 2.25, 2.96), 3.15 (95\% CI 2.57, 3.86) and 1.24 (95\% CI 1.14, 1.34), respectively. In South Asian women there was a significant increase in $\mathrm{PE}<37$ weeks (odds ratio $1.52,95 \%$ CI 1.15, 1.97) and $\mathrm{PE}<34$ 
weeks (odds ratio 1.84, 95\% CI 1.24, 2.64), but no significant difference from white women in total PE or GH. In women of East Asian and mixed racial origin there was no significant difference from white women in $\mathrm{PE}$ or GH.

The multiple logistic regression analysis demonstrated that in addition to black racial origin, increased risk for $\mathrm{PE}$ was provided by increasing maternal age and weight, conception by IVF, history of chronic hypertension and diabetes type 1, family history of PE and previous pregnancy affected by PE; the risk for PE decreased with increasing height, cigarette smoking, and previous birth of small for gestational age neonate. Similar findings were observed for GH, except for conception by IVF and history of chronic hypertension and diabetes, which did not have a significant contribution.

\section{Systematic review and meta-analysis}

\section{Data sources}

The search identified 3,654 potentially relevant citations, but 3,635 were excluded because they were nonrelevant articles, abstracts or letters rather than peer-reviewed papers, case-control studies, review articles, opinions or guidelines, studies providing data on a mixture of singleton and twin pregnancies or a mixture of $\mathrm{PE}$ and GH, and studies on parts of the same population (Figure 1). In total, only 19 studies were considered to be relevant and their data were combined with ours for the meta-analysis ${ }^{4-22}$. All 20 studies reported on PE in white women, 17 in black women, 8 on South Asian women and 6 on East Asian women.

\section{Methodological quality of the selected studies}

The methodological quality of the selected studies, assessed by the with QUIPS tool, ${ }^{34}$ is illustrated in Figure S1. Only two of the 19 previous studies were considered to be at low-risk of bias; 5 were at moderate-risk of bias and 12 were at high-risk of bias. The main problem with most studies is that they did not adjust for confounders.

\section{Nature of the studies}

All 19 included studies were unselected, they were confined to singleton pregnancies and they all used definitions of PE that necessitated the presence of hypertension in combination with proteinuria.

\section{Meta-analysis for comparison of rate of preeclampsia in white and other racial groups.}

The prevalence of PE for each study, weighted pooled data and heterogeneity between studies are provided in Figures 2, S2 and S3. In the meta-analysis of the combined data from 16 studies in the literature and the FMF study the RR for PE in black women, compared to white women was 1.68 (95\% CI 1.48, 1.92), but the heterogeneity of the studies was $98 \%$ (Figure 2). Publication bias was graphically assessed in Figure S4. The funnel plot showed no obvious asymmetry, but small studies are likely not published.

In the combined data from eight studies, the incidence of PE in women of South Asian racial origin, compared to white women, was not significantly different (RR 1.08, 95\% CI 0.97, 1.21); the heterogeneity between studies was 30\% (Figure S2). In the combined data from six studies, the incidence of PE in women of East Asian origin, compared to white women, was lower (RR 0.71, 95\% CI 0.56, 0.89); the heterogeneity between studies was $64 \%$ (Figure S3).

Only three previous studies provided adjusted ORs and the results of the combined meta-analysis from these four studies and our study are shown in Figures 3, S5 and S6. In black, compared to white women, the adjusted OR for PE was 1.90 (95\% CI 1.61, 2.23). In women of South Asian racial origin, compared to white women, the adjusted OR for PE was 1.28 (95\% CI 1.19, 1.38). In women of East Asian racial origin, there was no significant difference from white women in the incidence PE, after adjustment for confounding factors.

\section{DISCUSSION}

\section{Main findings}


There are four main findings from the large FMF prospective study in women with singleton pregnancies living in England. First, multiple logistic regression analysis demonstrated that in addition to black racial origin, increased risk for PE is provided by increasing maternal age and weight, conception by IVF, history of chronic hypertension and diabetes type 1, family history of PE and previous pregnancy affected by PE; the risk for PE decreases with increasing height, cigarette smoking, and previous birth of small for gestational age neonate. Second, in black women, compared to white women, after adjustment for elements of maternal characteristics and medical history there is a 2-fold, 2.5-fold and 3-fold higher risk of total PE, preterm PE and early PE, respectively, and a $25 \%$ increase in the risk of GH. Third, in women of South Asian racial origin, compared to white women, there is a 1.5-fold higher risk of preterm and early PE but no significant difference in total PE or GH. Fourth, in women of East Asian racial origin, compared to white women, there is no significant difference in the risk of $\mathrm{PE}$ or GH.

The literature search identified only 19 studies that provided data on the incidence of PE in some of the racial groups as defined by the FMF study. In the assessment of the quality of the included studies only two were considered to be at low risk of bias. In the meta-analyses of data from previous studies combined with those of the FMF study the unadjusted risk of PE in black women, compared to white women was higher and in women of East Asian origin, compared to white women, the risk was lower; in women of South Asian racial origin, compared to white women, the risk was not significantly different. However, in the meta-analysis of three previous studies that provided adjusted ORs, albeit with adjustment for very few relevant maternal characteristics, combined with our data the risk of PE in women of black and South Asian racial origin, compared to white women, was increased, whereas in East Asian women the risk of PE was not significantly different from that in white women.

\section{Strengths and limitations}

The main strengths of the FMF study are first, prospective examination of a large population of women with singleton pregnancies attending for routine pregnancy care at 11-13 weeks' gestation, second, we recorded maternal and pregnancy characteristics that have previously been reported to be associated with development of hypertensive disorders of pregnancy, third, we used a recently updated definition of PE which requires the development of hypertension with either proteinuria or renal insufficiency, hepatic dysfunction, thrombocytopenia, neurological complications or pulmonary edema, ${ }^{28}$ and fourth, we carried out multiple logistic regression analysis and found that significant independent contribution to $\mathrm{PE}$, in addition to racial origin, was provided by maternal age, weight, height, method of conception, smoking, history of chronic hypertension or diabetes, parity, family history of PE, previous pregnancy affected by PE or birth of small for gestational age neonate.

A limitation of the FMF study is that racial origin was classified into five broad categories and it is likely that there would be variations in outcome in subgroups within each category, such as different regions of Africa and between African and Caribbean women classified as black.

The main limitations of the study relate to the findings of the systematic review of the literature and metaanalysis. For example, 16 studies provided data on the comparison of the incidence of PE between black and white women and although in most the incidence in black women was higher, the heterogeneity between studies was 98\%; furthermore, only two of the studies reported adjusted ORs and adjustments were made for very few of the maternal characteristics. Similarly, there were only seven studies reporting on South Asian women and five on East Asian women, by comparison with white women and only two of these studies reported adjusted ORs. Consequently, although the combined data included more than 800 thousand black women and more than two million white women, the meta-analysis does not provide useful information on the true contribution of black race to the prediction of PE because of the heterogeneity between studies and the lack of adjustment for confounders in most of the studies; the same is true for women of South Asian and East Asian racial origin.

\section{Interpretation of results and implications for clinical practice}

The observed patterns of racial differences in development of hypertensive disorders of pregnancy are consis- 
tent with those observed in the development of cardiovascular diseases in non-pregnant women. ${ }^{39}$ In a large UK registry of 1,068,318 patients between 1997 and 2010 from 225 general practices across England, black, compared to white patients, were more likely to present with ischaemic stroke and intracerebral haemorrhage while South Asian patients had significantly higher hazard ratios for angina and myocardial infarction. ${ }^{40}$ This study also showed that the median age of first cardiovascular disease diagnosis was substantially lower in women of black and South Asian racial origin than white women.

Prediction of PE and GH necessitates first, data obtained from large prospective observational studies with accurate recording of maternal demographic characteristics and medical history and the appropriate infrastructure for obtaining the necessary outcome measures, and second, multiple logistic regression analysis which defines the independent contribution of each risk factor. The data from the FMF study fulfil these criteria and there are several elements from the maternal history that contribute to PE and GH; in defining the specific contribution of one risk factor, such as black racial origin, it is essential that all other factors are taken into account. In the development of the FMF competing risks model for prediction of PE a wide range of maternal factors are taken into account to derive the prior risk which is then adjusted with the addition of biomarkers to obtain the posteriorrisk. ${ }^{41}$

This systematic review and meta-analysis has highlighted the weakness of such approach in defining the contribution of one specific risk factor such as racial origin. Although the combined number of patients arising from such studies can be very large the heterogeneity between individual studies and the lack or minimal adjustment for confounders produces results that cannot be used for accurate prediction of the outcome under investigation.

\section{Conclusions}

In women of black racial origin, compared to white women, the risk of GH is $25 \%$ higher and the risk of $\mathrm{PE}$ is 2-fold higher after adjustment for confounding factors in maternal characteristics and medical history. In women of South Asian origin, the risk of preterm PE is 1.5-fold higher than in white women. Accurate assessment of the contribution of different racial groups to the prediction of $\mathrm{PE}$ necessitates prospective examination of pregnancies and appropriate adjustment for confounders rather than meta-analyses of heterogeneous studies with no or minimal adjustment for confounders.

Acknowledgements: This study was supported by grants from the Fetal Medicine Foundation (UK Charity No: 1037116). This body had no involvement in the study design; in the collection, analysis and interpretation of data; in the writing of the report; and in the decision to submit the article for publication. The search of the literature for the metanalysis was conducted by Mrs Sonya Di Giorgio, Clinical Support Librarian, King's College London, UK.

Disclosure of interests: The authors report no conflict of interest.

Contribution to authorship: KHN and AA conceptualized and designed the study and wrote the first draft of the paper. AS and RA were involved in the sample collection for the FMF study. AA and DV carried out the systematic review of the literature and quality assessment of the selected articles. MMG conducted the statistical analysis. All authors revised and contributed to the intellectual content of the manuscript.

Details of ethics approval: The study was approved by the UK NHS Research Ethics Committee (REC reference: 02-03-033 on $11^{\text {th }}$ March 2003).

\section{REFERENCES}

1. GBD 2015 Maternal Mortality Collaborators. Global, regional, and national levels of maternal mortality, 1990-2015: a systematic analysis for the Global Burden of Disease Study 2015. Lancet2016; 388: $1775-1812$.

2. GBD 2015 Child Mortality Collaborators. Global, regional, national, and selected subnational levels of stillbirths, neonatal, infant, and under-5 mortality, 1980-2015: a systematic analysis for the Global Burden of Disease Study 2015. Lancet 2016; 388: 1725-1774. 
3. Wright D, Syngelaki A, Akolekar R, Poon LC, Nicolaides KH. Competing risks model in screening for preeclampsia by maternal characteristics and medical history. Am J Obstet Gynecol 2015; 213: 62.e1-10.

4. Bryant AS, Seely EW, Cohen A, Lieberman E. Patterns of pregnancy-related hypertension in black and white women. Hypertens Pregnancy 2005; 24: 281-190.

5. Caughey AB, Stotland NE, Washington AE, Escobar GJ. Maternal ethnicity, paternal ethnicity, and parental ethnic discordance: predictors of preeclampsia. Obstet Gynecol 2005; 106: 156-161.

6. Bodnar LM, Catov JM, Klebanoff MA, Ness RB, Roberts JM. Prepregnancy body mass index and the occurrence of severe hypertensive disorders of pregnancy. Epidemiology 2007; 18: 234-239.

7. Goetzinger KR, Singla A, Gerkowicz S, Dicke JM, Gray DL, Odibo AO. Predicting the risk of preeclampsia between 11 and 13 weeks' gestation by combining maternal characteristics and serum analytes, PAPP-A and free $\beta$-hCG. Prenat Diagn 2010; 30: 1138-1142.

8. Di Lorenzo G, Ceccarello M, Cecotti V, Ronfani L, Monasta L, Vecchi Brumatti L, Montico M, D'Ottavio G. First trimester maternal serum PIGF, free $\beta$-hCG, PAPP-A, PP-13, uterine artery Doppler and maternal history for the prediction of preeclampsia. Placenta 2012; 33: 495-501.

9. Gong J, Savitz DA, Stein CR, Engel SM. Maternal ethnicity and pre-eclampsia in New York City, 1995-2003. Paediatr Perinat Epidemiol 2012; 26: 45-52.

10. Zhang S, Cardarelli K, Shim R, Ye J, Booker KL, Rust G. Racial disparities in economic and clinical outcomes of pregnancy among Medicaid recipients. Matern Child Health J 2013; 17: 1518-1525.

11. Lisonkova S, Joseph KS. Incidence of preeclampsia: risk factors and outcomes associated with earlyversus late-onset disease. Am J Obstet Gynecol 2013; 209: 544.e1-544.e12.

12. Park FJ, Leung CH, Poon LC, Williams PF, Rothwell SJ, Hyett JA. Clinical evaluation of a first trimester algorithm predicting the risk of hypertensive disease of pregnancy. Aust $N Z$ J Obstet Gynaecol 2013; 53: 532-539.

13. Moon M, Odibo A. First-trimester screening for preeclampsia: impact of maternal parity on modeling and screening effectiveness. J Matern Fetal Neonatal Med 2015; 28: 2028-2033.

14. Flores KF, Robledo CA, Hwang BS, Leishear K, Laughon Grantz K, Mendola P. Does maternal asthma contribute to racial/ethnic disparities in obstetrical and neonatal complications? Ann Epidemiol 2015; 25:392-397.

15. Gabbay-Benziv R, Oliveira N, Baschat AA. Optimal first trimester preeclampsia prediction: a comparison of multimarker algorithm, risk profiles and their sequential application. Prenat Diagn 2016; 36: $34-39$.

16. Al-Amin A, Rolnik DL, Black C, White A, Stolarek C, Brennecke S, da Silva Costa F. Accuracy of second trimester prediction of preterm preeclampsia by three different screening algorithms. Aust $N Z$ J Obstet Gynaecol 2018; 58: 192-196.

17. Rezende KBC, Cunha AJLAD, Amim Junior J, Bornia RG. External validation of the Fetal Medicine Foundation algorithm for the prediction of preeclampsia in a Brazilian population. Pregnancy Hypertens 2019; 17: 64-68.

18. Ross KM, Dunkel Schetter C, McLemore MR, Chambers BD, Paynter RA, Baer R, Feuer SK, Flowers E, Karasek D, Pantell M, Prather AA, Ryckman K, Jelliffe-Pawlowski L. Socioeconomic Status, Preeclampsia Risk and Gestational Length in Black and White Women. J Racial Ethn Health Disparities $2019 ; 6: 1182-1191$.

19. Sutton EF, Rogan SC, Lopa S, Sharbaugh D, Muldoon MF, Catov JM. Early Pregnancy Blood Pressure Elevations and Risk for Maternal and Neonatal Morbidity. Obstet Gynecol 2020; 136: 129-139.

20. Anderson NH, Sadler LC, Stewart AW, Fyfe EM, McCowan LM. Ethnicity, body mass index and risk of pre-eclampsia in a multiethnic New Zealand population. Aust N Z J Obstet Gynaecol 2012; 52: $552-558$.

21. Farrar D, Santorelli G, Lawlor DA, Tuffnell D, Sheldon TA, West J, Macdonald-Wallis C. Blood pressure change across pregnancy in white British and Pakistani women: analysis of data from the Born in Bradford cohort. Sci Rep 2019; 9: 13199.

22. Mañé L, Flores-Le Roux JA, Gómez N, Chillarón JJ, Llauradó G, Gortazar L, Payà A, Pedro-Botet J, 
Benaiges D. Association of first-trimester HbA1c levels with adverse pregnancy outcomes in different ethnic groups. Diabetes Res Clin Pract 2019; 150: 202-210.

23. Khalil A, Rezende J, Akolekar R, Syngelaki A, Nicolaides KH. Maternal racial origin and adverse pregnancy outcome: a cohort study. Ultrasound Obstet Gynecol 2013; 41: 278-285.

24. Robinson HP, Fleming JE. A critical evaluation of sonar crown rump length measurements. Br J Obstet Gynaecol 1975; 82: 702-710.

25. Nicolaides KH. Screening for fetal aneuploidies at 11 to 13 weeks. Prenat Diagn 2011; 31: 7-15.

26. Syngelaki A, Hammami A, Bower S, Zidere V, Akolekar R, Nicolaides KH. Diagnosis of fetal nonchromosomal abnormalities on routine ultrasound examination at 11-13 weeks' gestation. Ultrasound Obstet Gynecol 2019; 54: 468-476.

27. Nicolaides KH, Wright D, Syngelaki A, Wright A, Akolekar R. Fetal Medicine Foundation fetal and neonatal population weight charts. Ultrasound Obstet Gynecol 2018; 52: 44-51.

28. American College of Obstetricians and Gynecologists, and the Task Force on Hypertension in Pregnancy. Hypertension in Pregnancy. Obstet Gynecol 2013; 122: 1122-1131.

29. The R Foundation. R: The R Project for Statistical Computing. Published 2018. https://www.rproject.org/

30. DerSimonian R, Laird N. Meta-analysis in clinical trials. Control Clin Trials 1986; 7: 177-188.

31. Higgins JP, Thompson SG. Quantifying heterogeneity in a meta-analysis. Stat Med 2002; 21: 1539-1558.

32. Sterne JA, Egger M, Smith GD. Systematic reviews in health care: Investigating and dealing with publication and other biases in meta-analysis. BMJ 2001; 323: 101-105. 24.

33. Peters JL, Sutton AJ, Jones DR, Abrams KR, Rushton L. Comparison of two methods to detect publication bias in meta-analysis. JAMA2006; 295: 676-680.

34. Hayden JA, van der Windt DA, Cartwright JL, Cote P, Bombardier C. Assessing bias in studies of prognostic factors. Ann Intern Med2013; 158: 280-286.

35. R Core Team (2021). R: A language and environment for statistical computing. R Foundation for Statistical Computing, Vienna, Austria. URL https://www.R-project.org/.

36. Balduzzi S, Rücker G, Schwarzer G. How to perform a meta-analysis with R: a practical tutorial, Evidence-Based Mental Health ; 2019; 22: 153-160.

37. Fox J, Weisberg S (2019). An $\{\mathrm{R}\}$ Companion to Applied Regression, Third Edition. Thousand Oaks CA: Sage. URL: https://socialsciences.mcmaster.ca/jfox/Books/Companion/

38. Viechtbauer, W. Conducting meta-analyses in $\mathrm{R}$ with the metafor package. Journal of Statistical Software 2010; 36: 1-48. URL: https://www.jstatsoft.org/v36/i03/

39. British Heart Foundation (2010). Ethnic differences in cardiovascular disease 2010. London: British Heart Foundation. Available at:

www.bhf.org.uk/informationsupport/publications / /statistics/ethnic-differences-in-cardiovascular-disease2010 (accessed on 30 December 2021).

George J, Mathur R, Shah AD, Pujades-Rodriguez M, Denaxas S, Smeeth L, Timmis A, Hemingway H. Ethnicity and the first diagnosis of a wide range of cardiovascular diseases: Associations in a linked electronic health record cohort of 1 million patients. PLoS One 2017; 12: e0178945.

Wright D, Wright A, Nicolaides KH. The competing risk approach for prediction of preeclampsia. Am $J$ Obstet Gynecol 2020; 223: 12-23.e7.

\section{FIGURE LEGENDS}

Figure 1. Flow chart for the systematic review.

Figure 2. Forest plots of risk ratio for preeclampsia in women of black racial origin compared to white women with $95 \%$ confidence intervals (CI) and weighted pooled summary statistics using bivariate random-effects model.

Figure 3. Forest plots of odds ratio for preeclampsia in women of black racial origin compared to white women with $95 \%$ confidence intervals (CI) and pooled summary statistics using bivariate random-effects 
model.

Figure S1. Summary of the quality of included studies using the quality in prognostic studies (QUIPS) tool.

Figure S2. Forest plots of risk ratio for preeclampsia in women of South Asian racial origin compared to white women with $95 \%$ confidence intervals (CI) and weighted pooled summary statistics using bivariate random-effects model.

Figure S3. Forest plots of risk ratio for preeclampsia in women of East Asian racial origin compared to white women with $95 \%$ confidence intervals (CI) and weighted pooled summary statistics using bivariate random-effects model.

Figure S4. Funnel plots demonstrating assessment of publication bias of studies reporting on the incidence of preeclampsia in women of black and white racial origin. Each dot represents a study; the y-axis represents study precision (standard error) derived from the number of experimental subjects and the $\mathrm{x}$-axis shows the study's result (risk ratio).

Figure S5. Forest plots of odds ratio for preeclampsia in women of South Asian racial origin compared to white women with $95 \%$ confidence intervals (CI) and pooled summary statistics using bivariate randomeffects model.

Figure S6. Forest plots of odds ratio for preeclampsia in women of East Asian racial origin compared to white women with $95 \%$ confidence intervals (CI) and pooled summary statistics using bivariate randomeffects model.

Table 1. Characteristics of the study population

\begin{tabular}{|c|c|c|c|c|c|c|c|c|c|}
\hline \multicolumn{3}{|c|}{ White } & Black & \multirow{2}{*}{$\begin{array}{l}\begin{array}{l}\text { South } \\
\text { Asian }\end{array} \\
(\mathrm{N}=7834)\end{array}$} & \multirow{2}{*}{$\begin{array}{l}\begin{array}{l}\text { South } \\
\text { Asian }\end{array} \\
\text { P- } \\
\text { value }\end{array}$} & \multirow{2}{*}{$\begin{array}{l}\text { East } \\
\text { Asian } \\
(\mathrm{N}=3218)\end{array}$} & \multirow{2}{*}{$\begin{array}{l}\begin{array}{l}\text { East } \\
\text { Asian }\end{array} \\
\text { P- } \\
\text { value }\end{array}$} & \multirow{2}{*}{$\begin{array}{l}\text { Mixed } \\
(\mathrm{N}=4403)\end{array}$} & \\
\hline & & $(\mathrm{N}=25749)$ & $\begin{array}{l}\mathrm{P}- \\
\text { value }\end{array}$ & & & & & & F \\
\hline \multicolumn{9}{|c|}{$\begin{array}{l}\text { Hypertensive } \\
\text { disease }\end{array}$} & \\
\hline $\begin{array}{l}\text { Total } \\
\mathrm{PE}\end{array}$ & $\begin{array}{l}2708 \\
(2.1)\end{array}$ & $\begin{array}{l}1228 \\
(4.8)\end{array}$ & $<0.001$ & $\begin{array}{l}185 \\
(2.4)\end{array}$ & 0.162 & $\begin{array}{l}63 \\
(2.0)\end{array}$ & 0.570 & $\begin{array}{l}88 \\
(2.0)\end{array}$ & \\
\hline $\begin{array}{l}\mathrm{PE} \text { at } \\
<37 \\
\text { weeks }\end{array}$ & $\begin{array}{l}618 \\
(0.5)\end{array}$ & $\begin{array}{l}388 \\
(1.5)\end{array}$ & $<0.001$ & $\begin{array}{l}65 \\
(0.8)\end{array}$ & $<0.001$ & $\begin{array}{l}13 \\
(0.4)\end{array}$ & 0.519 & $\begin{array}{l}21 \\
(0.5)\end{array}$ & \\
\hline GH & $\begin{array}{l}3135 \\
(2.5)\end{array}$ & $\begin{array}{l}862 \\
(3.3)\end{array}$ & $<0.001$ & $\begin{array}{l}179 \\
(2.3)\end{array}$ & 0.367 & $\begin{array}{l}61 \\
(1.9)\end{array}$ & 0.049 & $\begin{array}{l}107 \\
(2.4)\end{array}$ & \\
\hline $\begin{array}{l}\text { Age } \\
\text { (years) }\end{array}$ & $\begin{array}{l}31.2 \\
(26.8, \\
35.0)\end{array}$ & $\begin{array}{l}30.6 \\
(26.5, \\
34.9)\end{array}$ & $<0.001$ & $\begin{array}{l}31.5 \\
(28.1 \\
34.9)\end{array}$ & $<0.001$ & $\begin{array}{l}32.6 \\
(29.1, \\
36.1)\end{array}$ & $<0.001$ & $\begin{array}{l}30.5 \\
(25.5, \\
34.6)\end{array}$ & \\
\hline $\begin{array}{l}\text { Height } \\
(\mathrm{cm})\end{array}$ & $\begin{array}{l}165 \\
(161, \\
170)\end{array}$ & $\begin{array}{l}165 \\
(160, \\
169)\end{array}$ & $<0.001$ & $\begin{array}{l}160 \\
(155, \\
163)\end{array}$ & $<0.001$ & $\begin{array}{l}160 \\
(156, \\
164)\end{array}$ & $<0.001$ & $\begin{array}{l}164 \\
(160, \\
169)\end{array}$ & \\
\hline $\begin{array}{l}\text { Weight } \\
(\mathrm{kg})\end{array}$ & $\begin{array}{l}67.0 \\
(59.7 \\
77.0)\end{array}$ & $\begin{array}{l}73.5 \\
(64.0 \\
85.0)\end{array}$ & $<0.001$ & $\begin{array}{l}61.0 \\
(54.6, \\
70.0)\end{array}$ & $<0.001$ & $\begin{array}{l}57.0 \\
(52.0 \\
63.8)\end{array}$ & $<0.001$ & $\begin{array}{l}66.0 \\
(59.0 \\
76.0)\end{array}$ & \\
\hline $\begin{array}{l}\text { Conception } \\
\text { by IVF }\end{array}$ & $\begin{array}{l}3642 \\
(2.9)\end{array}$ & $\begin{array}{l}265 \\
(1.0)\end{array}$ & $<0.001$ & $\begin{array}{l}273 \\
(3.5)\end{array}$ & 0.001 & $\begin{array}{l}110 \\
(3.4)\end{array}$ & 0.064 & $\begin{array}{l}93 \\
(2.1)\end{array}$ & \\
\hline
\end{tabular}




\begin{tabular}{|c|c|c|c|c|c|c|c|c|c|}
\hline \multicolumn{3}{|c|}{ 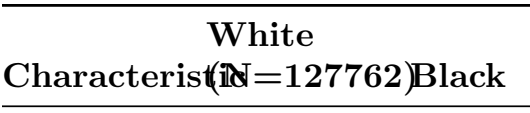 } & \multirow{3}{*}{$\frac{\text { Black }}{<0.001}$} & \multirow{3}{*}{$\begin{array}{l}\begin{array}{l}\text { South } \\
\text { Asian }\end{array} \\
84 \\
(1.1)\end{array}$} & \multirow{3}{*}{$\begin{array}{l}\begin{array}{l}\text { South } \\
\text { Asian }\end{array} \\
0.993\end{array}$} & \multirow{3}{*}{$\begin{array}{l}\begin{array}{l}\text { East } \\
\text { Asian }\end{array} \\
29 \\
(0.9)\end{array}$} & \multirow{3}{*}{$\begin{array}{l}\begin{array}{l}\text { East } \\
\text { Asian }\end{array} \\
0.420\end{array}$} & \multirow{3}{*}{$\begin{array}{l}\text { Mixed } \\
23 \\
(0.5)\end{array}$} & \multirow{3}{*}{$\frac{\mathrm{N}}{<}$} \\
\hline Conception a & $\mathrm{aft} 360$ & 170 & & & & & & & \\
\hline $\begin{array}{l}\text { ter } \\
\text { ovula- } \\
\text { tion } \\
\text { drugs }\end{array}$ & $(1.1)$ & $(0.7)$ & & & & & & & \\
\hline Smoking & $\begin{array}{l}13855 \\
(10.8)\end{array}$ & $\begin{array}{l}1020 \\
(4.0)\end{array}$ & $<0.001$ & $\begin{array}{l}90 \\
(1.1)\end{array}$ & $<0.001$ & $\begin{array}{l}44 \\
(1.4)\end{array}$ & $<0.001$ & $\begin{array}{l}432 \\
(9.8)\end{array}$ & \\
\hline $\begin{array}{l}\text { Chronic } \\
\text { hypertension }\end{array}$ & $\begin{array}{l}1182 \\
(0.9)\end{array}$ & $\begin{array}{l}891 \\
(3.5)\end{array}$ & $<0.001$ & $\begin{array}{l}101 \\
(1.3)\end{array}$ & 0.002 & $\begin{array}{l}20 \\
(0.6)\end{array}$ & 0.091 & $\begin{array}{l}44 \\
(1.0)\end{array}$ & \\
\hline $\begin{array}{l}\text { Diabetes } \\
\text { melli- } \\
\text { tus Type } \\
1\end{array}$ & $\begin{array}{l}622 \\
(0.5)\end{array}$ & $\begin{array}{l}62 \\
(0.2)\end{array}$ & $<0.001$ & $\begin{array}{l}21 \\
(0.3)\end{array}$ & 0.008 & $5(0.2)$ & 0.010 & $\begin{array}{l}15 \\
(0.3)\end{array}$ & \\
\hline $\begin{array}{l}\text { Diabetes } \\
\text { melli- } \\
\text { tus Type } \\
2\end{array}$ & $\begin{array}{l}541 \\
(0.4)\end{array}$ & $\begin{array}{l}519 \\
(2.0)\end{array}$ & $<0.001$ & $\begin{array}{l}200 \\
(2.6)\end{array}$ & $<0.001$ & $\begin{array}{l}37 \\
(1.1)\end{array}$ & $<0.001$ & $\begin{array}{l}33 \\
(0.7)\end{array}$ & \\
\hline SLE/APS & $\begin{array}{l}262 \\
(0.2)\end{array}$ & $\begin{array}{l}78 \\
(0.3)\end{array}$ & 0.003 & $\begin{array}{l}27 \\
(0.3)\end{array}$ & 0.013 & $4(0.1)$ & 0.420 & $8(0.2)$ & \\
\hline $\begin{array}{l}\text { Family } \\
\text { history } \\
\text { of PE }\end{array}$ & $\begin{array}{l}5887 \\
(4.6)\end{array}$ & $\begin{array}{l}980 \\
(3.8)\end{array}$ & $<0.001$ & $\begin{array}{l}232 \\
(3.0)\end{array}$ & $<0.001$ & $\begin{array}{l}54 \\
(1.7)\end{array}$ & $<0.001$ & $\begin{array}{l}191 \\
(4.3)\end{array}$ & \\
\hline Nulliparous & $\begin{array}{l}61899 \\
(48.4)\end{array}$ & $\begin{array}{l}9653 \\
(37.5)\end{array}$ & $<0.001$ & $\begin{array}{l}3634 \\
(46.4)\end{array}$ & $<0.001$ & $\begin{array}{l}1622 \\
(50.4)\end{array}$ & 0.0297 & $\begin{array}{l}2106 \\
(47.8)\end{array}$ & \\
\hline Parous & $\begin{array}{l}65863 \\
(51.6)\end{array}$ & $\begin{array}{l}16096 \\
(62.5)\end{array}$ & & $\begin{array}{l}4200 \\
(53.6)\end{array}$ & & $\begin{array}{l}1596 \\
(49.6)\end{array}$ & & $\begin{array}{l}2297 \\
(52.2)\end{array}$ & \\
\hline $\begin{array}{l}\text { Parous, } \\
\text { previ- } \\
\text { ous } \\
\text { PE }\end{array}$ & $\begin{array}{l}3829 \\
(3.0)\end{array}$ & $\begin{array}{l}1208 \\
(4.7)\end{array}$ & $<0.001$ & $\begin{array}{l}229 \\
(2.9)\end{array}$ & 0.735 & $\begin{array}{l}46 \\
(1.4)\end{array}$ & $<0.001$ & $\begin{array}{l}113 \\
(2.6)\end{array}$ & \\
\hline $\begin{array}{l}\text { Parous, } \\
\text { previ- } \\
\text { ous } \\
\text { SGA }\end{array}$ & $\begin{array}{l}7530 \\
(5.9)\end{array}$ & $\begin{array}{l}2830 \\
(11.0)\end{array}$ & $<0.001$ & $\begin{array}{l}1032 \\
(13.2)\end{array}$ & $<0.001$ & $\begin{array}{l}291 \\
(9.0)\end{array}$ & $<0.001$ & $\begin{array}{l}390 \\
(8.9)\end{array}$ & \\
\hline
\end{tabular}

Values are given as median (interquartile range) or number (\%); PE, preeclampsia; GH, gestational hypertension; IVF, in vitro fertilisation; SLE, systemic lupus erythematosus; APS, antiphospholipid syndrome; SGA, small for gestational age $<10^{\text {th }}$ percentile

Table 2. Odds ratios obtained from univariable and multiple logistic regression analysis demonstrating association of maternal racial origin with preeclampsia. In the multivariable analysis there was adjustment for confounding factors in maternal demographic characteristics and medical history.

\begin{tabular}{lllll}
\hline Hypertensive disorder & Maternal racial origin & Maternal racial origin & Maternal racial origin & M \\
\hline & Black & South Asian & East Asian & M \\
Univariable analysis & & & & \\
Preeclampsia $(\mathrm{n}=4272)$ & $2.31(2.16,2.48)^{*}$ & $1.12(0.96,1.29)$ & $0.92(0.71,1.18)$ & 0. \\
Preeclampsia $<37$ weeks $(\mathrm{n}=1105)$ & $3.15(2.77,3.57)^{*}$ & $1.72(1.32,2.21)^{*}$ & $0.83(0.46,1.38)$ & 0.
\end{tabular}




\begin{tabular}{|c|c|c|c|}
\hline Hypertensive disorder & Maternal racial origin & Maternal racial origin & Maternal racial origin \\
\hline Preeclampsia $<34$ weeks $(\mathrm{n}=482)$ & $3.98(3.28,4.80)^{*}$ & $2.24(1.53,3.17)^{*}$ & $0.99(0.39,2.03)$ \\
\hline Gestational hypertension $(\mathrm{n}=4344)$ & $1.38(1.27,1.49)^{*}$ & $0.93(0.80,1.08)$ & $0.77(0.59,0.98)^{*}$ \\
\hline \multicolumn{4}{|l|}{ Multivariable analysis } \\
\hline Preeclampsia $(\mathrm{n}=4272)$ & $1.99(1.85,2.14)^{*}$ & $1.08(0.92,1.26)$ & $1.05(0.80,1.34)$ \\
\hline Preeclampsia $<37$ weeks $(\mathrm{n}=1105)$ & $2.58(2.25,2.96)^{*}$ & $1.52(1.15,1.97)^{*}$ & $0.88(0.48,1.48)$ \\
\hline Preeclampsia $<34$ weeks $(\mathrm{n}=482)$ & $3.15(2.57,3.86)^{*}$ & $1.84(1.24,2.64)^{*}$ & $0.95(0.37,1.97)$ \\
\hline Gestational hypertension $(\mathrm{n}=4344)$ & $1.24(1.14,1.35)^{*}$ & $1.01(0.86,1.17)$ & $0.93(0.71,1.19)$ \\
\hline
\end{tabular}

Comparison of each maternal racial origin group was with those of white racial origin. Values are given as odds ratio (95\% confidence interval). *Significant at $\mathrm{p}<0.05$.

\section{APPENDIX 1 Search strategies}

Ovid MEDLINE(R) ALL <1946 to August 10, 2021>

1 exp african continental ancestry group/ or american native continental ancestry group/ or asian continental ancestry group/ or oceanic ancestry group/ or exp European Continental Ancestry Group/

2 (african-american* or caucasian* or black* or white* or african-caribbean* or afro-caribbean* or asian* or BAME or latin* or hispanic*).mp.

31 or 2

4 hypertension, pregnancy-induced/ or pre-eclampsia/

5 (pre?eclampsi* or (gestational adj1 hypertension) or (hypertensive disease adj1 pregnan*) or (hypertensi* adj4 pregnan*)).ti,ab.

64 or 5

73 and 6

8 exp animals/ not humans.sh.

$97 \operatorname{not} 8$

10 limit 9 to english language

\section{Embase $<1974$ to 2021 Week 31>}

1 exp african/ or exp black person/ or asian continental ancestry group/ or ancestry group/ or asian american/ or british asian/ or caucasian/ or hispanic/ or indigenous people/ or oceanic ancestry group/ or european/ or exp central european/ or exp eastern european/ or exp northern european/ or exp southern european/ or exp western european/

2 (african-american* or caucasian* or black* or white* or african-caribbean* or afro-caribbean* or asian* or BAME or latin* or hispanic*).mp.

31 or 2

4 maternal hypertension/ or preeclampsia/

5 (pre?eclampsi* or (gestational adj1 hypertension) or (hypertensive disease adj1 pregnan*) or (hypertensi* adj4 pregnan*)).ti,ab.

64 or 5

73 and 6 
8 (exp animals/ or exp invertebrate/ or animal experiment/ or animal model/ or animal tissue/ or animal cell/ or nonhuman/) and (human/ or normal human/ or human cell/)

9 exp animals/ or exp invertebrate/ or animal experiment/ or animal model/ or animal tissue/ or animal cell/ or nonhuman/

$109 \operatorname{not} 8$

117 not 10

12 limit 11 to english language

13 limit 12 to exclude Medline records

Cinahl database 1981 - present

S1 MH "Ethnic Groups+"

S2 african-american* or caucasian* or black* or white* or african-caribbean* or afro-caribbean* or (east N1 asian*) or (south N1 asian*) or asian* or mixed race or BAME or latin* or hispanic*

S3 S1 OR S2

S4 MH "Pregnancy-Induced Hypertension" or MH "Pregnancy-Induced Hypertension"

S5 pre?eclampsi* or (gestational N1 hypertension) or (hypertensive disease N1 pregnan*) or (hypertensi* N4 pregnan*)

S6 S4 OR S5

S7 S3 AND S6

S8 MH Animals+

S9 MH (ANIMAL STUDIES)

S10 TI (ANIMAL MODEL*)

S11 S8 OR S9 OR S10

S12 MH (HUMAN)

S13 S11 not S12

S14 S7 not S13

S15 S7 not S13

Emcare 1995 - present

1 exp AFRICAN/ OR "AFRICAN AMERICAN"/ OR "AFRICAN BRAZILIAN" /

2 exp ASIAN/ OR "ASIAN AMERICAN"/ OR "ASIAN CONTINENTAL ANCESTRY GROUP" /

3 exp "OCEANIC ANCESTRY GROUP"/

4 exp EUROPEAN/

5 (african-american* OR caucasian* OR black* OR white* OR african-caribbean* OR afro-caribbean* OR (east ADJ1 asian*) OR (south ADJ1 asian*) OR asian* OR mixed race OR BAME OR latin* OR hispanic*).ti,ab

6 (1 OR 2 OR 3 OR 4 OR 5)

7 "MATERNAL HYPERTENSION" / OR PREECLAMPSIA/ 
8 (pre?eclampsi* OR (gestational ADJ1 hypertension) OR (hypertensive disease ADJ1 pregnan*) OR (hypertensi* ADJ4 pregnan*)).ti,ab

9 (7 OR 8)

10 (6 AND 9)

11 exp ANIMAL/

$12 \exp$ HUMAN/

1311 not 12

1410 not 13

1514 [English language]

\section{Cochrane library reviews}

1. african-american* or caucasian* or black* or white* or african-caribbean* or afro-caribbean* or (east NEAR/1 asian*) or (south NEAR/1 asian*) or asian* or mixed race or BAME or latin*

2. pre?eclampsi* or (gestational NEAR/1 hypertension) or (hypertensive disease NEAR/11 pregnan*) or (hypertensi* NEAR/4 pregnan*)

3. 1 and 2

\section{Hosted file}

Race and PE BJOG.pptx available at https://authorea.com/users/458571/articles/555087maternal-racial-origin-and-preeclampsia-cohort-study-and-systematic-review-with-metaanalysis 